\title{
Geomorphometric analysis of landform pattern using topographic position and ASTER GDEM
}

\begin{abstract}
A number of research have been carried out on geomorphology using a conventional approach to classify the landform; this has a tendency of producing misleading result, due to ruggedness and inaccessibility of the terrain. Geographic Information System (GIS) and remote sensing techniques are capable of generating automated landform classes using Topographic Position Index techniques (TPI). This research is set to achieve the following objectives: to categorize landform elements and to illustrate the complexity of the terrain in Negeri Sembilan state based on ASTER GDEM with $30 \mathrm{~m}$ resolution. TPI-based algorithm for landscape classification was applied to slope position and landform classification automation. We used 300 and 3000 neighbourhood size on the TPI grids to determine the landform categories. To quantify the spatial pattern of topographic position, Deviation from mean elevation (DEV) is adopted. Maximum Elevation Deviation was selected to measure the spatial landscape pattern at the maximum (3000) scale of the absolute DEV value within the scale (DEVmax), and finally, high-pass filter algorithm was used to identify the extreme topography (ridges/valleys). The combination of the TPI and slope position of DEV that formed the landform classification results show four prominent landform classes these include canyons, U-shape valley, local ridges/ hill valleys, and mountaintops/high ridges. The slope position classes revealed only two (valley/cliff base and ridges/canyons edge) classes based on slope position index. The canyons had the maximum of $63 \%$ and minimum was Ushaped valley with $1.04 \%$ for the landform of the area of interest. To achieve better results, there is a need to utilize a high spatial resolution remotely sensed DEM derived data and sensitivity analysis need to be incorporated. For that, laser scanning data is capable of improving the results.
\end{abstract}

Keyword: Geomorphometeric; Landform pattern; GIS; ASTER; Remote sensing; Malaysia 